\title{
Insights on Narrative Analysis from a Study of Racial Microaggressions and Microaffirmations
}

\author{
Rosalie Rolón-Dow ${ }^{1}$ and Michelle J. Bailey \\ University of Delaware, USA
}

\begin{abstract}
Stories that document the experiences of individuals are central to narrative research methods. Like narrative research, critical race theory $(C R T)$ also values the experiential knowledge that can be documented through storytelling. CRT scholars, however, particularly focus on the use of storytelling to document how race and racism are understood and experienced by racially minoritized groups. As researchers, including CRT scholars, use narrative methods, they face many complex choices about which data analysis methods to use and how to use them. In this article, the authors feature a CRT research project to provide examples of three strategies they used for analyzing narrative data: restorying, typology development and classification, and memoing. The authors demonstrate the process of restorying to streamline participant narratives for a clearer understanding. They show the use of a typology for organization and exploration of stories based on common themes. And they outline how analytic memoing lends itself to exploring participant narratives more deeply by writing about them using consistent prompts. Overall, this article emphasizes working with whole narratives, understanding narratives as stories, and acknowledging participants and their narratives as a source of knowledge. While these analytic strategies can be applied to a wide range of research topics, the project featured in this article shows their potential and close alignment with research projects that employ a CRT framework.
\end{abstract}

KEYWORDS: narrative research analysis, restorying, typology, analytic memos, Critical Race Theory.

Researchers using narrative methods value the experiences and understandings people convey through stories about their lives and view stories as important in providing insights about social issues (Clandinin, 2006; Connelly \& Clandinin, 1990; Green, 2013). Although stories are ubiquitous in everyday life (Clandinin, 2016), narrative researchers face many complex choices about which data analysis methods to use and how to use them (Rogan \& de Kock, 2005). Riessman (2008) describes narrative analysis as "a family of methods for interpreting texts that have in common a storied form" (p. 11). Yet, there is little consensus on how narratives should be analyzed (Ahmed, 2013). Narrative researchers center story as the analysis anchor, but they must also remain open to a variety of ways of working with storied forms of data as they engage in the messy and non-linear analytic process (Bruce et al., 2016).

${ }^{1}$ Corresponding Author: Rosalie Rolón-Dow is Associate Professor in the College of Education and Human Development at the University of Delaware. E-Mail: rosa@udel.edu 
Furthermore, qualitative researchers ought to share public examples of their data analysis processes, including the ways that researchers create meaning and produce texts from their narrative data (Anfara et al., 2002; Davidson et al., 2017; Mello, 2002; O'Connor \& Joffe, 2020; Peshkin, 2000). Methods transparency can expose researchers to a broad analytic tool menu and enhance trustworthiness in qualitative research (Anfara et al., 2002; Hemmler et al., 2020). For qualitative researchers using narrative approaches, exposure to analytic strategies from a variety of narrative projects can help them expand their interpretive analytic toolbox and increase their capacity for treating their data in meaningful and fruitful ways (Sandelowski, 2011).

This article features the data analysis strategies used in a study that investigated the racial microaggressions and microaffirmations that racially minoritized students experienced in university settings. The study lent itself to the use of narrative methods because we sought to add nuance and depth to the microaggression and microaffirmation concepts, to explore the personal meanings that students attach to microaggression and microaffirmation experiences, and to understand how these experiences influenced the way students understood and navigated the racial dynamics of their campuses. The study serves as an exemplar because the range of research questions we addressed required us to employ a variety of narrative analysis strategies. Furthermore, the study is rooted in a critical race theory (CRT) framework. Given that CRT places high value on storytelling to highlight the marginalized experiential knowledge of people of color, it is fitting to use this study as an exemplar of narrative analysis strategies. The goal of this article is thus to contribute to researchers' analytic toolbox by describing several data analysis strategies from the featured narrative research project.

\section{Literature Review}

The "narrative turn" (Goodson \& Gill, 2011) in social science research has led to the increasing popularity of narrative methods across many disciplines, including health (Lapum et al., 2010; Mellor et al., 2020), social work (Nygren \& Blom, 2001) and education (James, 2018; Langa et al., 2021; Pazey, 2020; Persaud, 2019). In this literature review, we will examine how scholars consider the myriad choices they must make in narrative research, with particular attention to four main themes: (a) holistic narrative analysis; (b) literary elements in participant narratives; (c) restorying and reconfiguration processes; and (d) critical perspectives in narrative work.

Polkinghorne (1995) theorizes two modes of analysis in narrative research: "analysis of narratives" and "narrative analysis" (pp. 5-6). While the former is more akin to traditional methods of coding, in which the researcher breaks participant narratives down into smaller units and sorts them by theme, the latter is a more holistic approach, as it involves the use of the entire narrative (Polkinghorne, 1995). While narrative researchers can and do combine traditional coding methods with narrative analysis, we explore narrative analysis more deeply here because it is more reflective of both the literature and the "narrative turn" (Goodson \& Gill, 2011; Pinnegar \& Daynes, 2012).

Mello (2002) argues that the best way to fully understand a narrative and manage researcher bias is to examine the narrative in its entirety. For Polkinghorne (1995), analyzing narratives in their entirety acknowledges both the "special characteristics" of each narrative, as well as the "relational significance" of the events within a narrative (p. 7, 11). In other words, solely relying on traditional coding methods not only misses the important ways in which each narrative is distinct, but also overlooks the ways in which events within a narrative build on and relate to one another. Price et al. (2013) argue that analyzing narratives in their entirety maintains the "complexity" of participants' experiences and stories, rather than attempting to distill them by coding (p. 308). This is not to say, however, that whole narratives cannot or should not be coded 
or categorized. In our example study, for example, we will explore the use of typologies, a method of categorizing narratives.

Analyzing narratives holistically naturally lends itself to literary heuristics. Participant narratives are stories and contain the literary elements found in other types of stories: characters, setting, and plot (Coulter \& Smith, 2009; James, 2018; Lapum et al., 2010; Mello, 2002; Polkinghorne, 1995; Rogan \& de Kock, 2005). Polkinghorne (1995) uses the term "emplotment" to describe how these literary elements facilitate analysis. Plot ties events together and signals the bounds of the story (Polkinghorne, 1995). Combined with characters and setting, plot can be a powerful tool to flesh out the complexities of participant experiences by describing "the interrelationship of temporal sequence, human motivation, chance happenings, and changing interpersonal and environmental context" (Polkinghorne, 1995, p. 7).

However, participants rarely tell their stories linearly. Often, it is up to the researcher to bring "narrative coherence" to participant stories (James, 2018). One way in which coherence can be achieved is through "restorying" (Ollerenshaw \& Creswell, 2002). Restorying will be described in more detail below, but it typically involves retelling or restructuring individual narratives for clearer or more enhanced understanding (Ollerenshaw \& Creswell, 2002). Some researchers take a further step, which Polkinghorne (1995) calls "narrative configuration," in which they use common themes and patterns found across multiple sources of data to construct larger narratives. While our example study does not employ narrative configuration, it is important to note how other critical scholars in the field use this process. Polkinghorne himself does not frame narrative configuration this way; however, many critical researchers use their participants' narratives to construct counterstories: representative stories that are often directly juxtaposed against preexisting dominant narratives (see Pazey, 2020; Persaud, 2019; Puente, 2020; Rodriguez, 2011; Wagaman et al., 2018).

As used by CRT researchers, counterstories are not confined to a narrative configuration approach. They can either draw from multiple sources of data or be contained within a single source. CRT researchers value counterstories because they center the experiential knowledge of people of color, illustrate the central nature of race and racism and challenge dominant ideologies of colorblindness and neutrality (Solórzano \& Yosso, 2002). In our exemplar study, the student narratives created from each interview are counterstories because they highlight experiences of racially minoritized students that challenge notions of fair, neutral, or colorblind higher education spaces.

By centering participant knowledge and agency, narrative analysis also challenges the dominant narrative in academia about who has the authority to create knowledge (i.e., higher education faculty) and who does not (i.e., research participants or community members) (Beals et al., 2020; Delgado Bernal, 2002; Huber et al., 2013; Lessard et al., 2018; Mueller, 2019; Pazey, 2020; Solórzano \& Yosso, 2002; Wagaman et al., 2018). This is largely why many studies with critical frameworks, including our example study, employ this type of analysis (see, Diaz et al., 2021; Langa et al., 2021; Pazey, 2020; Rodriguez, 2011; Wagaman et al., 2018). Narrative analysis inherently emphasizes and values participant knowledge because participants are often more familiar with the topic of inquiry than researchers (Wilinsky \& McCabe, 2021).

However, when communicating findings, narrative researchers must also ensure that they are portraying participants in a way that reflects how participants perceive and represent themselves (Lessard et al., 2018). Many narrative researchers emphasize researcher reflexivity and a careful consideration of researcher-participant dynamics (Coulter \& Smith, 2009; Lessard et al., 2018). Coulter and Smith (2009), for example, argue that the power dynamics underlying the researcherparticipant relationship influence how the participant tells their narrative. Narratives do not exist in a vacuum, but rather, in relation to the teller and the listener, as well as in wider social, cultural, 
and historical contexts (Diaz et al., 2021; James, 2018; Lessard et al., 2018; Mello, 2002). Therefore, researchers must constantly negotiate their own position relative to that of their participants. This negotiation allows the researcher to situate themself clearly within their research, rather than be tempted to adopt an "objective" tone that might indicate a non-existent authority over participants' narratives (Coulter \& Smith, 2009). Ultimately, the researcher has the privilege of disseminating the narrative to an audience, and therefore has the responsibility of analyzing and discussing participant narratives thoughtfully, sticking close to the words of the participants, and not extrapolating or assuming too much of participants' intentions (Coulter \& Smith, 2009).

The theoretical underpinnings of narrative analysis are important in understanding the decisions researchers make for how to analyze their narrative data. While the key themes discussed above inform our own conceptions of narrative research, we also briefly discuss other important decisions in narrative work, such as narrative size and scope, and strategies for categorizing and visualizing data. Some studies utilize narratives that are longer in nature, such as biographies of participants' careers (Kelchtermans, 1993) or even their entire lives (Mellor et al., 2020). Others, like Georgakopoulou (2006), work with "small" stories, such as allusions to events--or even refusals to tell a story. The scope of the stories in our study is similar to what Bullough and Pinnegar (2001) call "nodal moments," or pivotal moments that lead the participant to see something in a new or different way, often shaping their view about a particular topic. In terms of categorizing, organizing, and visualizing narrative data, some authors, such as Van de Mieroop (2020) and Smith and Sparkes (2008), create models based on various aspects of their narratives and organize their narratives accordingly. Others, such as Lapum et al. (2010) and Price et al. (2013), lay out their narratives using "story maps," visual representations of stories akin to those used to teach basic plot structure in elementary school. As we will discuss in more detail below, our example study utilized a typology system for organizing participant narratives along common themes.

Mello (2002) calls for more in-depth explanations that outline how narrative research is done, arguing that the specificities of "analyzing data and creating meaning" are not discussed as frequently as they should be (p. 233). With this in mind, we see this work as situated within a line of scholarship that provides detailed demonstrations of analytic approaches used in narrative studies (see Catalano \& Creswell, 2013; Fraser, 2004; Mello, 2002; Mueller, 2019; Ollerenshaw \& Creswell, 2002; Persaud, 2019; Rogan \& de Kock, 2005; Spector-Mersel, 2011). Through the description of three analytic tools used in our study - restorying, typology development and classification, and memoing - we demonstrate a holistic and practical way to analyze narrative data that is mindful of the narrative analysis principles above.

\section{Description of Exemplar Project}

The exemplar research project was undertaken to better understand the relationship between racial microaggressions, microaffirmations, and student perceptions of campus racial climate. Racial microaggressions are words, actions, or even environmental cues that stereotype, insult, or invalidate racially minoritized people in the course of their everyday lives (Pierce, 1974; Sue et al., 2007). Racial microaffirmations, on the other hand, are words, actions, or environmental cues experienced by racially minoritized people that affirm racial identities, acknowledge racialized realities, resist racism, or advance racial justice (Rolón-Dow \& Davison, 2018; Rolón-Dow \& Davison, 2021).

Critical race theory (CRT) provided the framework for the project, both in the way we understood the study's core concepts and, in the storytelling, methodological approach we used to document, analyze, and learn from the microaggression and microaffirmation experiences that students shared. Methods that acknowledge students of color as creators of knowledge (Delgado 
Bernal, 2002; Solórzano \& Yosso, 2002) and document the narratives they share are central in CRT methodologies (Delgado, 1989; Malagon et al., 2009). As such, the respect for ordinary lived experience that is fundamental in narrative research (Clandinin, 2016) aligns well with critical race theory (CRT), which prioritizes the experiential knowledge of racially minoritized groups in its efforts to explicate the ways race and racism function in everyday life (Delgado \& Stefancic, 2017, Delgado Bernal, 2002).

The project consisted of two studies with the same framework and methodological approach. The first study, in 2016-2017, involved two rounds of data collection at a university in the United States (U.S.) and included both undergraduate and graduate students. The second study, in 2018-2019, expanded data collection sites to include the university from study one, an additional U.S. university, and a small U.S. college.

Sixty-eight undergraduate students who self-identified as Black, Latinx or mixed race participated in the studies. Each student was invited to share a story of a microaggression and a story of a microaffirmation. The research team included one faculty member, two graduate students, and five undergraduate students. An additional faculty member and an additional graduate student were invited into the research team to work on data analysis. Throughout the research process, team members participated in learning modules facilitated by the lead researcher that included attention to narrative methodology, the study's conceptual framework, our positionalities and how they influenced the research process, and data analysis exercises.

Narrative interviews encourage participants to retell stories about important events, the social context in which they occur, and the feelings associated with them (Muylaert et al., 2014). This project prioritized stories of racialized experiences from students' perspectives. Focusing on stories also communicated value for the distinctive knowledge that individuals from racially minoritized groups contribute to understandings of campus climate. This project sought to maximize the potential of narratives to "help bring order out of chaos, provide explanations for unexpected events, and also spark reflection, critique, and rearticulation of events" (Freeman, 2016, p. 36). Finally, personal narratives were prioritized because the story format can encourage empathy and highlight the humanity of others (Huber et al., 2013), key elements of producing research that can deepen understandings of the ways racial dynamics are lived and felt by students from racially minoritized backgrounds and identities.

The stories in this project are constituted from often brief, but significant, everyday racialized experiences. Bullough and Pinnegar (2001) argue that teachers using self-study methods that produce narratives must focus on critical "nodal moments" that shape their teaching journeys. The notion of "nodal moments" is helpful in explaining the scope of the stories that are the focus of this project. Different from narrative researchers who spend extended periods of time with a small number of participants, we sought to gather stories of nodal moments from multiple participants.

To encourage participants to share more openly, all interviews were conducted by student researchers. We explained the study's concepts in language familiar to students. While the interviews were semi-structured in nature, allowing interviewers to be responsive to the different ways students narrated their experiences, the protocol included questions and prompts that ensured there was some uniformity in the information gathered about each participant's experiences with microaggressions and microaffirmations. These prompts included attention to elements of a storyline such as people involved; context for experience; beginning, middle and end of interaction; actions or words spoken by people involved; meaning of event to the storyteller; and affective responses to the interaction. Attention to consistency in gathering these details across the interviews lent itself to a cohesive set of stories relevant to the study's research purposes (Kim, 2016). The interviews lasted from 30 to 60 minutes and were transcribed upon completion. 


\section{Three Strategies for Analysis}

Given the nature of narrative research, it is imperative that researchers employ analysis strategies that reflect a value for the lived experiences of participants and that draw on the strength of understanding those experiences holistically. Mello (2002) argues that analytic strategies should preserve the essential qualities, authenticity, and substance of narratives. We employed strategies to work with each story as a holistic unit and to consider comparison across the stories in relation to the research questions. In what follows, we describe three analytic strategies for working with narratives, illustrating each one with examples from our study.

\section{Analysis as Restorying}

The first analytic exercise involved working with the transcribed interview to produce a short story of each of the experiences shared by participants. Individuals rarely share experiences in a chronological, cohesive manner. Rather, as a storyteller recalls and shares details about an event, they may go back and forth between elements of their experience. Indeed, as participants reflect on a prior lived experience, the meanings that experience holds for them may unfold and shift in the retelling process (Connelly \& Clandinin, 1990), often creating a messy and nonlinear transcript. The telling of stories is also a negotiated and interactional encounter in which the storyteller responds to the interviewer, who may ask clarification questions or simply encourage the storyteller through short prompts or nonverbal responses. Restorying the interview transcript involves [re]configuring data into a coherent storyline that includes context information, interactions, events, characters, thoughts, and feelings (Ollerenshaw \& Creswell, 2002). In this process, the researcher both prepares the data in a narrative format that is conducive to additional forms of narrative analysis and makes the stories told through interviews more accessible to the audience the researcher seeks to reach (Seidman, 2013).

There are different approaches and goals in restorying data; our process had elements of the three-dimensional approach described by Ollerenshaw and Creswell (2002). In this approach, the researcher prioritizes the description of individual experiences as they occur through social interactions and situations. The purpose of the restorying process is to communicate why and how things happened in a holistic way that helps the readers understand the significance of an event from the perspective of the main character-in this case, the research participant (Kim, 2016). While the participants' words are central in the construction of the stories, it is also important to note what role the researcher plays in the telling of the story and in the restorying process. In this study, we both created the conditions for the storytelling encounters and then were the primary authors that constructed the stories from the interview transcripts.

For our restorying process, we completed three rounds of editing. The interview format lends itself to presenting the story from a first-person perspective, which we used to help the reader feel closer to the participant and to avoid falling into the trap of extrapolating too much from the story (Seidman, 2013). In the first edit, we removed the interviewer's questions and paid attention to basic formatting issues, such as paragraph breaks and punctuation. We also added words in brackets as needed to ensure all parts of the transcript were comprehensible. We divided the transcript into two main parts that corresponded with the way the interview was structured: (a) the retelling of the students' experience and (b) reflections about how the experience shaped the students' thinking about themselves and about the racial dynamics of their campus. In this first editorial exercise, we also deleted any parts of the transcript that were completely irrelevant to the story. 
In the second edit, we considered the best way to retell the story so that it could easily be understood by anyone unfamiliar with the interview. As illustrated by the sample story (see Table 1), in this step, we paid attention to inclusion of the following elements in the story: (a) context (where interaction took place), (b) characters (who was involved), (c) interaction or plot (what happened first, next, last), (d) affective responses, (e) post-interaction (anything that happened afterwards related to experience), and (f) reflection response (participant's thoughts and feelings after retelling the story). Integrating these elements helped us ensure a consistent format in the restorying process, which was helpful for subsequent analysis activities. In this step, we re-ordered portions of the transcript, as needed, to ensure that the reader could follow the order of the events in each story and that they understood the context, characters involved, and the ways the story was significant to the storyteller.

\section{Table 1}

\section{Restoried Interview}

Story: "Why are you asking me?"

Story Elements

This is like a class of probably 50 students and the professor was white. I was one of the few minorities in that specific class that was about Health. They were just talking about the different Hispanic demographics [and] the rising rate of obesity and how community really influences people's health. The professor said, "Can you speak about that?" I was just taken aback a little bit. No one else was asked about white America. I had never experienced that, especially because I wasn't in the front row; she literally had to point me out; I was sitting towards the side of the door.

It was weird because then all eyes are on me again, and that's just too much pressure for me. At that moment, I didn't know what to say. I was annoyed by the fact that I was being called out with that specific thing, being Hispanic and having to talk about something generalized to the Hispanic population. Who am I to even speak on that? I'm just one of so many. I just responded to the professor, "I don't know how to answer that question." She was surprised [when I said that]. So, then she was giving different situations like, "When you're at family gatherings, do you guys feel like you're more of a community or la comunidad?" And [she] was trying to speak Spanish. I was just thinking that If you say 'the community, I understand it's the community, I don't think you have to translate it to Spanish. I thought that was really weird. I felt like she was prying too much, in front of the class to be asking me all these questions, it was weird and it was unnecessary. Literally the whole entire class turned to me and they're just expecting me to be elaborate and to give them the information. So, I was just like, "I don't know exactly what you want me to say." That's what I said in front of the whole class.

[Afterwards], I talked to a friend about it but I never approached the professor.

Context and Characters

Interaction (what happened first)

\section{Affective \\ Responses}

Interaction (What happened next)

\section{Affective \\ Responses}

Interaction (what happened last)

Post-experience (Responses and 
[Thinking about it now], I just feel like that was stupid, like why did she even ask that question. There's other people in the class that probably could have talked if they've experienced anything like that or explain it and then approach the question differently instead of calling me out on it.

\begin{tabular}{l|l}
$\begin{array}{l}\text { feelings following } \\
\text { experience) } \\
\text { Reflection } \\
\text { response } \\
\text { (participant's } \\
\text { thoughts and } \\
\text { feelings when } \\
\text { asked how they } \\
\text { think about } \\
\text { experience after } \\
\text { retelling it) }\end{array}$ \\
\hline
\end{tabular}

The third edit involved fine-tuning the story. To ensure that we adequately captured the participants' experiences, we shared drafts with participants, who were encouraged to suggest any changes, additions, or deletions before we finalized the stories. The restorying process led to the creation of two brief (one- to two-page) stories per participant. While most transcripts included all of the elements we sought to capture, there were slight differences in the thoroughness of the interviewer in eliciting detail-rich and comprehensive transcripts and in the storytelling style used by different participants. Subsequently, there were slight variations in the length and depth of the stories.

The restorying process in this project primarily involved formatting, arranging, and condensing interview data with the goal of presenting it in a more accessible and concise story that illustrates and respects the participant's experience. We drew on only one source of data per story. However, other researchers may employ aspects of the restorying process to create stories from multiple sources of data. Regardless of the scope of the data set, researchers engaged in restorying must continually make decisions about which data are pertinent to the research questions and about how to present that data. The analytic restorying process can also set the stage for other forms of analysis or can prepare the data into stories that can then be used for other purposes. ${ }^{2}$

\section{Analysis as Typology Development and Classification}

\section{Typology Development}

Typologies are helpful in conceptualizing constructs and their characteristics; in understanding variation within data; and in understanding how different types of a phenomena relate to research questions, to participants' characteristics, or to a study's context. For example, typologies helped us analyze how different types of microaggressions or microaffirmations shaped students' perceptions of their universities' racial climate and helped us examine contextual features in settings (e.g., classrooms, student residences, or student organizations) that shaped experiences. We drew on existing typologies (Sue et al, 2007; Yosso et al., 2009) to classify each microaggression story into one of four categories: microinsult, microinvalitation, microassault, or institutional microaggression. However, for the microaffirmation stories, we had to create our own typology (Rolón-Dow \& Davison, 2021). This interpretive analysis involved examining the stories

\footnotetext{
${ }^{2}$ In this project, for example, the vignettes were featured in a radio show to illustrate the concepts of microaggressions and microaffirmations and were used to provide professional development to members of the university's residential life program.
} 
to understand what made certain types of microaffirmations fit into a "type" and what distinguished these types one from another.

Researchers need to consider what element of their phenomena they want to prioritize in developing a typology. Some possible elements that could be considered include the setting where the experience occurs, the content of the interaction, or the motivations of the person(s) involved in the interaction (for example, the motivations of the person enacting the affirmation). Since our project primarily focused on understanding experiences that promote the success of racially minoritized groups from the perspectives of individuals belonging to those groups, we prioritized the impact the experiences had on the student and the ways they described feeling affirmed.

The first step in developing a microaffirmation typology involved having research team members carefully read the stories from the first study. Individual team members recorded short phrases describing the impact of the microaffirmation on the recipient or on some aspect of their experience (see Table 2, Columns A and B, for example). The research team then looked across the stories, noting if and how there were similarities in the ways microaffirmation experiences impacted students. We thus added a third column to our table (see Table 2: Column C) that helped us group stories together that had similar impact on participants.

\section{Table 2}

Typology development step 1

A. Topic of story $\quad$ B. Impacts on recipient $\quad$ C. Type of impact

Marisol's participation in a club - Is excited to find like-minded peers Experiences in which
for Spanish speakers who want to nurture their students' racial/ethnic bilingualism identities are made known, - Switching between languages appreciated, or included normalized

- Space where Spanish is important without being tokenized or

- Feels sense of community, sense of exploited being insider

This process is not entirely different from typical forms of qualitative data analysis where researchers explore similarities in their codes and then group them into broader categories. However, an essential difference is that in narrative typology development, the focus is always on the whole story. As we grouped stories together and checked how they fit our emerging classification system, we often re-read the whole story rather than only working with coded portions of stories. This process of working with the stories, as opposed to working exclusively with story chunks, is helpful in preserving the integrity of the narrative and enhancing the researcher's understanding and analysis (Mello, 2002).

As we divided the initial stories into several groups based on "type of impact" (Table 1, Column C), we paid special attention to similarities and differences in "impact type." We identified four microaffirmation types, including microrecognitions, microvalidations, microtransformations, and microprotections. We drew on the story examples to create a standard definition for each type.

\section{Typology Classification}

Once we developed a typology, we sought to better understand if story classification was consistent across researchers. All the first study's stories were independently classified by three separate research team members. Team members then came together to discuss how they arrived at their classifications. We engaged in a process to ensure calibration of our typology application, 
like Hemmler et al's (2020) system of using discussion among multiple coders to calibrate a study's coding scheme through a consensus-based approach. Discussing differences in data interpretation between researchers can help researchers address questions, generate insights, and clarify distinctions between data and thus enhance the richness of data analysis and the quality and trustworthiness of a research study (Church et al., 2019; Hemmler et al., 2020).

We created a spreadsheet that showed each team member's story classifications side by side. Initially, there were multiple discrepancies in story classification between research team members. Team discussions revealed that differences in classification usually involved focusing attention on different elements of the story (rather than on the impact of the story) or perceiving that there were compelling reasons that some stories fit more than one classification type. The calibration process helped us notice that we needed a system for streamlining the story classification to gain greater consistency between researchers. We developed a rubric consisting of questions based on the typology definitions to guide us through a series of steps for classifying the stories (see Table 3 for example of the microaffirmation rubric). We then individually reclassified the stories using the rubric and found much more consistent classification across researchers.

\section{Table 3}

Microaffirmation Rubric

1. Story title

2. Read the story then answer the following question: What affirming action, verbal remark, situation, or environmental cue is the storyteller describing?

3. Answer the question or questions that seem the most relevant to this story.

a. In what way(s) did the storyteller feel or experience that their feelings or experiences related to their social identity(ies) or their group's experiences, history, or contemporary conditions were made known, made visible, appreciated, or included?

b. In what way(s) did the storyteller feel or experience that their thoughts, feelings, sensations, and behaviors associated with their social identity(ies) or their group's experiences, history, or contemporary conditions were accepted, corroborated, legitimized, or given value?

c. In what way(s) does the storyteller feel or experience that they, as a member of a particular social identity group, or the group(s) they belong to were further integrated into the institution, or that their capacity for success or some facet of their social or academic life were enabled, enhanced, or increased? In what way(s) did the recipient feel that a process, policy, or initiative addressed their experiences as a member of a particular social identity group? (One or both questions may apply to a particular story.)

d. In what way(s) does the storyteller describe that they were shielded or protected from harmful or derogatory behaviors, practices and policies tied to their individual or group identity(ies)? In what way(s) did the recipient feel support, advocacy, or intervention on their behalf? (one or both questions may apply to a particular story)

4. Classify your story based on which questions you answered for number

- Question "a" label the story a microrecognition

- Question "b" label the story a microvalidation

- Question "c" label the story a microtransformation

- Question "d" label the story a microprotection

5. If the story was labeled into more than one type, which category best captures the type of affirmation that you think the storyteller was trying to communicate?

6. Compare your classification of the story with team members. Discuss your rationale and thought process and calibrate any discrepancies. 
Developing a typology from the stories in our project helped us illustrate the range of experiences that are affirming to students. Similarly, other researchers may use the typology process to outline nuances, differences, or similarities in the phenomena they study through stories. Additionally, creating typology definitions can contribute to the work of other researchers studying similar topics.

\section{Analysis as Memoing}

As is common in different types of qualitative research, additional questions emerged as we gathered and analyzed data and read relevant literature. An article by Bonilla-Silva (2019) prompted us to consider racialized emotions in the context of the stories of microaggressions and microaffirmations. The stories we gathered lent themselves to this analysis since the narrative interview process demands attention to the affective components of experiences. Connelly and Clandinin (1990) explain "burrowing" as an analytic strategy in which stories are reconstructed from the person's point of view at the time of the event and as a strategy in which narrative researchers attend to the ways life events are associated with certain feelings and what the origin of these feelings might be. We used analytic memoing to burrow into our stories and pay attention to the emotions participants expressed as well as how these related to their racialized encounters. Memoing lends itself to immersive experiences with data that can increase a researcher's sensitivity to the meanings in the data. The two research team members working on the racialized emotions analysis developed a memo format (see Table 4) and wrote a memo per story answering six questions related to Bonilla-Silva's (2019) racialized emotions concept.

\section{Table 4}

Memo Format

Memo Questions

1. What racialized emotions does the storyteller name? (Bold the most prominent two and then elaborate.)

2. What racialized emotions are represented in story, in addition to that of storyteller? (Bold the most prominent two and then elaborate.)

3. What are the two most prevalent racialized emotions that we experience as we read the story?

4. Does the story reflect a hierarchical structure of racialized emotions? (Yes/no; if yes, elaborate.)

5. How do racialized emotions expressed in stories contribute to or reflect racialization of groups?

6. What are racialized emotions "doing" in the university context? (What behaviors are produced by racialized emotions or what racialized emotions are produced by behaviors?)

The goal for the memos was to help us identify if and how essential elements of the racialized emotions framework could be applied to enhance understanding of the participants' experiences with microaggressions and microaffirmations. We focused on identifying any racialized emotions present in the story, the hierarchical nature of the emotions, and the ways the emotions were functioning within the university space. We supported our answers to the memo questions with story excerpts. To parse out how our own positionality was impacting our interpretation of the stories, we also answered a question that asked us to identify the racialized emotions that we felt as we read and memoed about each participant's experience. 
We tested the memo format on a small group of stories. We then placed our memos side by side to assess whether our answers reflected a similar understanding of the memo questions and of the data used to support answers. Differences in answers nudged us to further explicate and clarify our interpretations, nurtured collaborative meaning-making about each question's meaning, and added nuance and depth to our understanding of the phenomena under study (Patel et al., 2016). After the memo comparison, we refined the memo questions, ensuring that each researcher had the same understanding of each question's purpose. We then used the refined memo format on the remaining stories.

Memos are well suited to exploring, contemplating, and challenging what is happening in the data (Birks et al., 2008); thus, memoing is helpful in moving from concrete data to emerging conceptual assertions. In our study, the use of memoing helped us understand the role and function of a specific phenomenon (racialized emotions) in the stories told by students. Once the memoing process was complete, we were then able to look at the phenomenon across the participants' stories and were better prepared to make and support analytic assertions in our writing. We anticipate that story memoing could be helpful to other researchers in similar ways. That is, researchers can memo about their stories to explore how a particular phenomenon is present in their data, to understand the role or function of that phenomenon, and to systematically develop analytic assertions with and about their narrative data.

\section{Conclusion}

In this article, we discussed the analysis strategies used in a narrative research project that highlighted stories of microaggressions and microaffirmations experienced by university students. We demonstrated how we navigated the middle ground between the collection of data and the development and presentation of our study's research findings. These detailed descriptions of analytic strategies can enhance the analytic toolbox available to researchers using similar methods.

In our study, the restorying process, an analytic exercise in and of itself, was fundamental to other types of analysis that we conducted. By restorying the interviews, we were able to create brief, accessible, engaging stories that could then be used for a variety of purposes. The restorying process also reflected the value that scholars using narrative methods or critical race theory place on stories as a way of knowing. The method of moving from interview transcript to a story is not as simple as it may first appear. Rather, it requires the researcher to carefully consider how to set up data gathering encounters that lend themselves to storytelling. Furthermore, the editing involved in the restorying process needs to be done in a way that authentically conveys the experiences shared by research participants.

The second type of analysis we explored was the development and use of typologies. These analytic exercises are helpful for researchers as they seek to deepen understandings of their research topics and as they explore both differences and commonalities in the stories or narratives that are part of their research. In our study, the typology analytic exercises added nuance and depth to our understandings of the range of actions, comments, and environmental cues that are considered microaggressions or microaffirmations. The analysis involved in classifying stories can also expand the questions researchers ask of their data. In the study presented here, for example, the typology helped us ask questions about the different types of microaffirmations in relation to the race identity of persons enacting microaffirmations, the context where the microaffirmations occurred, and the impact on students' views on campus climate. Researchers using typology development and classification to explore other topics can also expect that this analytic tool will help them understand nuances within the stories in their study and address a range of research questions about their different story types. 
Memoing, the third analytic exercise we described, is often used in the data collection phase of research. As described in this article, memoing is also a useful analytic tool to employ after data has been collected. Memoing provided a format for engaging in analytic notetaking with each story. As we demonstrated, memoing allowed us to systematically look across stories to address a research question; in our case, we explored racialized emotions. Importantly, it allowed us to do so while maintaining the holistic integrity of the storied data form. This process helped us move away from a close-up view of individual stories to examine the assertions we could make as we looked across the stories. However, because of the emphasis in narrative research on a holistic and contextual understanding of phenomena, we always returned to the stories themselves to illustrate the analytic insights unearthed through the memoing process.

Narrative research methods aligned particularly well with the purposes of our research project because, as CRT scholars, we seek to understand and illuminate how race and racism shape daily experiences of racially minoritized groups. An important implication of our work is that scholars utilizing qualitative methods to study race should consider when their research questions might best lend themselves to narrative data collection and analysis approaches. Data collection methods such as field observations, interviews, and focus groups are commonly used by qualitative researchers to gather participants' stories. Yet, researchers sometimes equate qualitative data analysis primarily with coding and thus prioritize working with smaller chunks of data rather than looking at data in more holistic ways (St. Pierre \& Jackson, 2014). This tendency to reduce storied data minimizes the potential that stories hold in generating analytic insights and demonstrating research findings.

The analysis strategies illustrated here may be useful to scholars conducting research on a wide range of topics and may be particularly relevant to researchers who seek to understand how race and other social identities influence the experiences of individuals or groups. In addition, researchers interested in the dynamic relationship between participants' experiences and the sociocultural contexts of their lives may benefit from employing narrative methods that allow them to analyze data in a holistic manner. These analytic strategies are especially helpful in revealing the authenticity, substance, and contextual understandings of participants' experiences.

Pellico and Chinn (2007) describe narrative as "a means of personal knowing and a means of illumination for those who analyze the stories" (p. 59). Scholars using narratives understand their powerful potential to provide insight and understanding about the lives of people in research, and they seek to share the "illumination" potential of stories with multiple audiences. But for narratives to live up to this promise, researchers must first engage in analyzing the stories that are entrusted to their care. The analytic process is rarely formulaic, and what may work in one study may not be helpful in another. Still, researchers working with narratives can benefit from detailed descriptions of analytic strategies employed in a variety of studies. Through exposure to a wide range of ways of analyzing narrative data, researchers can be better prepared to employ or adapt strategies that best fit their particular use of stories and their purposes. Furthermore, by making the analytic process used in studies transparent, the field of narrative research is enriched.

\section{Funding}

The research study described in this article received funding support from The Spencer Foundations' Small Grants Program and from University of Delaware's Center for the Study of Diversity. 


\section{References}

Ahmed, A. (2013). Structural narrative analysis: Understanding experiences of lifestyle migration through two plot typologies. Qualitative Inquiry, 19(3), 232-243. https://doi.org/10.1177/1077800412466050

Anfara, V. A., Brown, K. M., \& Mangione, T. L. (2002). Qualitative analysis on stage: Making the research process more public. Educational Researcher, 31(7), 28-38. https://doi.org/10.3102/0013189x031007028

Beals, F., Kidman, J., \& Funaki, H. (2020). Insider and outsider research: negotiating self at the edge of the emic/etic divide. Qualitative Inquiry, 26(6), 593-601. https://doi.org/10.1177/1077800419843950

Birks, M., Chapman, Y., \& Francis, K. (2008). Memoing in qualitative research: Probing data and processes. Journal of Research in Nursing, 13(1), 68-75. https://doi.org/10.1177/1744987107081254

Bonilla-Silva, E. (2019). Feeling race: Theorizing the racial economy of emotions. American Sociological Review, 84(1), 1-25. https://doi.org/10.1177/0003122418816958

Bruce, A., Beuthin, R., Sheilds, L., Molzahn, A., \& Schick-Makaroff, K. (2016). Narrative research evolving: Evolving through narrative research. International Journal of Qualitative Methods, 15(1), 1609406916659292. https://doi.org/10.1177/1609406916659292

Bullough Jr., R. V., \& Pinnegar, S. (2001). Guidelines for quality in autobiographical forms of selfstudy research. Educational Researcher, 30(3), 13-21. https://doi.org/10.3102/0013189X030003013

Catalano, T., \& Creswell, J. W. (2013). Understanding the language of the occupy movement: A cognitive linguistic analysis. Qualitative Inquiry, 19(9), 664-673. https://doi.org/10.1177/1077800413500931

Church, S. P., Dunn, M., \& Prokopy, L. S. (2019). Benefits to qualitative data quality with multiple coders: Two case studies in multi-coder data analysis. Journal of Rural Social Sciences, 34(1), 1-14. https://egrove.olemiss.edu/jrss/vol34/iss1/2

Clandinin, D. J. (2006). Narrative inquiry: A methodology for studying lived experience. Research Studies in Music Education, 27(1), 44-54. https://doi.org/10.1177/1321103x060270010301

Clandinin, D. J. (2016). Engaging in narrative inquiry. Routledge. https://doi.org/10.4324/9781315429618

Connelly, F. M., \& Clandinin, D. J. (1990). Stories of experience and narrative inquiry. Educational Researcher, 19(5), 214. https://doi.org/10.3102/0013189x019005002

Coulter, C.A., \& Smith, M.L. (2009). The construction zone: Literary elements in narrative research. Educational Researcher, 38(8),

577-590. https://doi.org/10.3102/0013189x09353787

Davidson, J., Thompson, S., \& Harris, A. (2017). Qualitative data analysis software practices in complex research teams: Troubling the assumptions about transparency and portability. Qualitative Inquiry, 23(10), 779-788. https://doi.org/10.1177/1077800417731082

Delgado Bernal, D. (2002). Critical race theory, Latino critical theory, and critical raced-gendered epistemologies: Recognizing students of color as holders and creators of knowledge. Qualitative Inquiry, 8(1), 105-126. https://doi.org/10.1177/107780040200800107

Delgado, R. (1989). Storytelling for oppositionists and others: A plea for narrative. Michigan Law Review, 87(8), 2411-2441. https://doi.org/10.2307/1289308 
Delgado, R., \& Stefancic, J. (2017). Critical race theory: An introduction. NYU Press. https://doi.org/10.2307/j.ctt1ggjjn3

Diaz, M. F., Cheng, S., Goodlad, K., Sears, J., Kreniske, P., \& Satyanarayana, A. (2021). Turning collective digital stories of the first-year transition to college into a web of belonging. American Journal of Qualitative Research, 5(1), 67-84. https://doi.org/10.29333/ajqr/10793

Fraser, H. (2004). Doing narrative research. Qualitative social work: Research and practice, 3(2), 179-201. https://doi.org/10.1177/1473325004043383

Freeman, M. 2016. Modes of thinking for qualitative data analysis. Taylor \&Francis. https://doi.org/10.4324/9781315516851

Georgakopoulou, A. (2006). Thinking big with small stories in narrative and identity analysis. Narrative Inquiry, 16(1), 122-130. https://doi.org/10.1075/ni.16.1.16geo

Goodson, I. F., \& Gill, S. R. (2011). The narrative turn in social research. Counterpoints, 386, 1733. https://www.jstor.org/stable/42981362

Green, B. (2013). Narrative inquiry and nursing research. Qualitative Research Journal, 13(1), 6271. https://doi.org/10.1108/14439881311314586

Hemmler, V. L., Kenney, A. W., Langley, S. D., Callahan, C. M., Gubbins, E. J., \& Holder, S. (2020). Beyond a coefficient: an interactive process for achieving inter-rater consistency in qualitative coding. Qualitative Research. Advance online publication. https://doi.org/10.1177/1468794120976072

Huber, J., Caine, V., Huber, M., \& Steeves, P. (2013). Narrative inquiry as pedagogy in education: The extraordinary potential of living, telling, retelling, and reliving stories of experience. Review of Research in Education,37(1), 212-242. https://doi.org/10.3102/0091732x12458885

James, G. (2018). A narrative inquiry perspective into coping mechanisms of international postgraduate students' transition experiences. American Journal of Qualitative Research, 2(1), 42-56. https://doi.org/10.29333/ajqr/5793

Kelchtermans, G. (1993). Getting the story, understanding the lives: From career stories to teachers' professional development. Teaching \& Teacher Education, 9(5/6), 443-456. https://doi.org/10.1016/0742-051x(93)90029-g

Kim, J. H. (2016). Understanding narrative inquiry: The crafting and analysis of stories as research. SAGE Publications. https://doi.org/10.4135/9781071802861

Langa, M., Wassermann, J., \& Maposa, M. (2021). Black African parents' narratives on apartheid schooling and school history. Perspectives in Education, 39(3), 3-16. https://doi.org/10.18820/2519593X/pie.v39.i3.2

Lapum, J., Angus, J. E., Peter, E., \& Watt-Watson, J. (2010). Patients' narrative accounts of openheart surgery and recovery: Authorial voice of technology. Social Science \& Medicine (1982), 70(5), 754-762. https://doi.org/10.1016/j.socscimed.2009.11.021

Lessard, S., Caine, V., \& Clandinin, D. J. (2018). Exploring neglected narratives: Understanding vulnerability in narrative inquiry. Irish Educational Studies, 37(2), 191-204. https://doi.org/10.1080/03323315.2018.1465835

Malagon, M. C., Huber, L. P., \& Velez, V. N. (2009). Our experiences, our methods: Using grounded theory to inform a critical race theory methodology. Seattle Journal for Social Justice, 8, 253-272.

Mello, R. A. (2002). Collocation analysis: A method for conceptualizing and understanding narrative data. Qualitative research, 2(2), 231-243. https://doi.org/10.1177/146879410200200206 
Mellor, R., Lancaster, K., \& Ritter, A. (2021). Recovery from alcohol problems in the absence of treatment: a qualitative narrative analysis. Addiction, 116(6), 1413-1423. https://doi.org/10.1111/add.15288

Mueller, R. A. (2019). Episodic narrative interview: Capturing stories of experience with a methods fusion. International Journal of Qualitative Methods, 18, 160940691986604. https://doi.org/10.1177/1609406919866044

Muylaert, C. J., Sarubbi Jr, V., Gallo, P. R., Neto, M. L. R., \& Reis, A. O. A. (2014). Narrative interviews: An important resource in qualitative research. Revista da Escola de Enfermagem da USP, 48(spe2), 184-189. https://doi.org/10.1590/s0080623420140000800027

Nygren, L. \& Blom, B. (2001). Analysis of short reflective narratives: a method for the study of knowledge in social workers' actions. Qualitative Research, 1(3), 369-384. https://doi.org/10.1177/146879410100100306

O'Connor, C., \& Joffe, H. (2020). Intercoder reliability in qualitative research: Debates and practical guidelines. International Journal of Qualitative Methods, 19, 1-13. https://doi.org/10.1177/1609406919899220

Ollerenshaw, J. A., \& Creswell, J. W. (2002). Narrative research: A Comparison of two restorying data analysis approaches. Qualitative Inquiry, 8(3), 329-347. https://doi.org/10.1177/10778004008003008

Patel, K., Auton, M. F., Carter, B., Watkins, C. L., Hackett, M., Leathley, M. J., \& Lightbody, C.E. (2016). Parallel-serial memoing: A novel approach to analyzing qualitative data. Qualitative health research, 26(13), 1745-1752. https://doi.org/10.1177/1049732315614579

Pazey, B. L. (2020). ¡Ya basta! Countering the effects of neoliberal reform on an urban turnaround high school. American Educational Research Journal, 57(4), 1868-1906. https://doi.org/10.3102/0002831219886530

Pellico, L. H., \& Chinn, P. L. (2007). Narrative criticism: A systematic approach to the analysis of story. Journal of Holistic Nursing, 25(1), 58-65. https://doi.org/10.1177/0898010106295188

Persaud, I. (2019). Insider and outsider analysis: Constructing, deconstructing, and reconstructing narratives of Seychelles' geography education. International Journal of Qualitative Methods, 18, 1-12. https://doi.org/10.1177/1609406919842436

Peshkin, A. (2000). The nature of interpretation in qualitative research. Educational Researcher, 29(9), 5-9. https://doi.org/10.3102/0013189x029009005

Pierce, C. (1974). Psychiatric problems of the Black minority. In S. Arieti (Ed.), American Handbook of Psychiatry (pp. 512-523). Basic Books.

Pinnegar, S., \& Daynes, G. (2012). Locating Narrative Inquiry historically: Thematics in the turn to narrative. In D.J. Clandinin (Ed.), Handbook of narrative inquiry: Mapping a methodology (pp. 3-34). SAGE Publications. https://doi.org/10.4135/9781452226552.n1

Polkinghorne, D. E. (1995). Narrative configuration in qualitative analysis. International Journal of Qualitative Studies in Education, 8(1), 5-23. https://doi.org/10.1080/0951839950080103

Price, S. L., Mcgillis Hall, L., Angus, J. E., \& Peter, E. (2013). Choosing nursing as a career: a narrative analysis of millennial nurses' career choice of virtue. Nursing Inquiry, 20(4), 305316. https://doi.org/10.1111/nin.12027

Puente, M. (2020). Leaving La Puente: A critical race counterstory of rural Chicana/Latina college choice. UCLA Journal of Education and Information Studies, 16(2). https://doi.org/10.5070/D4162046029

Riessman, C. K. (2008). Narrative methods for the human sciences. SAGE Publications. 
Rodriguez, T. L. (2011). Stories of self, stories of practice: Enacting a vision of socially just pedagogy for Latino youth. Teaching Education, 22(3), 239-254. https://doi.org/10.1080/10476210.2011.593165

Rogan, A. I., \& de Kock, D. M. (2005). Chronicles from the classroom: Making sense of the methodology and methods of narrative analysis. Qualitative Inquiry, 11(4), 628-649. https://doi.org/10.1177/1077800405276777

Rolón-Dow, R., \& Davison, A. (2018, May 21). Racial Microaffirmations: Learning from Student Stories of Moments that Matter. In J. M. Jones (Eds), Diversity Discourse: Research Briefs from the Center for the Study of Diversity (pp. 1-9). University of Delaware.

Rolón-Dow, R., \& Davison, A. (2021). Theorizing racial microaffirmations: a Critical Race/LatCrit approach. Race Ethnicity and Education, 24(2), 245-261. https://doi.org/10.1080/13613324.2020.1798381

Sandelowski, M. (2011). When a cigar is not just a cigar: Alternative takes on data and data analysis. Research in Nursing \& Health, 34(4), 342-352. https://doi.org/10.1002/nur.20437

Seidman, I. (2013). Interviewing as qualitative research: A guide for researchers in education and the social sciences. Teachers College Press.

Smith, B., \& Sparkes, A. C. (2008). Contrasting perspectives on narrating selves and identities: an invitation to dialogue. Qualitative $\quad$ Research, 8(1), 5-35. https://doi.org/10.1177/1468794107085221

Solórzano, D. G., \& Yosso, T. J. (2002). Critical race methodology: Counter-storytelling as an analytical framework for education research. Qualitative Inquiry, 8(1), 23-44. https://doi.org/10.1177/107780040200800103

Spector-Mersel, G. (2011). Mechanisms of selection in claiming narrative identities: A model for interpreting narratives. Qualitative inquiry, 17(2), 172-185. https://doi.org/10.1177/1077800410393885

St. Pierre, E. A., \& Jackson, A. Y. (2014). Qualitative data analysis after coding. Qualitative Inquiry, 20(6), 715-719. https://doi.org/10.1177/1077800414532435

Sue, D. W., Capodilupo, C. M., Torino, G. C., Bucceri, J. M., Holder, A., Nadal, K. L. \& Esquilin, M. (2007). Racial microaggressions in everyday life: Implications for clinical practice. American Psychologist, 62(4), 271. https://doi.org/10.1037/0003-066x.62.4.271

Van de Mieroop, D. (2020). The narrative dimensions model and an exploration of various narrative genres. Narrative Inquiry, 31(1), 1-24. https://doi.org/10.1075/ni.19069.van

Wagaman, M. A., Obejero, R. C., \& Gregory, J. S. (2018). Countering the norm, (re) authoring our lives: the promise counterstorytelling holds as a research methodology with LGBTQ youth and beyond. International Journal of Qualitative Methods, 17(1), 1-11. https://doi.org/10.1177/1609406918800646

Wilinsky, C. L., \& McCabe, A. (2021). Agency and communion in sexual abuse survivors' narratives. Narrative Inquiry, 31(1), 236-262. https://doi.org/10.1075/ni.20061.wil

Yosso, T., Smith, W., Ceja, M., \& Solórzano, D. (2009). Critical race theory, racial microaggressions, and campus racial climate for Latina/o undergraduates. Harvard Educational Review, 79(4), 659-691. https://doi.org/10.17763/haer.79.4.m6867014157m7071 


\section{Notes on Contributors}

Rosalie Rolón-Dow, Ph.D., is Associate Professor in the College of Education and Human Development at the University of Delaware. Her research focuses on the intersections of sociocultural identities and educational equity, and on the application of critical race theory to educational problems. Recent publications focus on racial literacy in teacher education; and racial microaggressions and microaffirmations in higher education. E-Mail: rosa@udel.edu.

Michelle J. Bailey is currently pursuing a doctoral degree in Education at the University of Delaware with a specialization in Sociocultural and Community-Based Approaches. She works as a graduate research assistant, and her research interests include spatial and geographic barriers to postsecondary education and college access for traditionally underrepresented students. E-Mail: mjbailey@udel.edu.

\section{ORCID}

Rosalie Rolón-Dow, https://orcid.org/0000-0002-1735-0563

Michelle J. Bailey, https://orcid.org/0000-0002-0450-5351

Manuscript received September 1, 2021

Final revision received November 20, 2021

Accepted November 26, 2021 